\title{
Severe refractory hypocalcaemia associated with osteoblastic metastatic breast carcinoma
}

Vikram Lal ${ }^{1}$, Simon Aswell ${ }^{1}$ Alison Humphrey ${ }^{2}$ Sath Nag ${ }^{1}$

1. Department of Diabetes and Endocrinology, 2. Department of Oncology

The James Cook University Hospital, Middlesbrough, UK

\section{Introduction}

Although hypercalcaemia is well frequently observed in people with metastatic malignancy, hypocalcaemia is a rare complication of osteoblastic metastases and occurs most commonly with breast and prostate carcinoma.
South Tees Hospitals WHS NHS Foundation Trust

\section{Case}

- A 46-yr-old woman with metastatic breast carcinoma and osteoblastic skeletal metastases treated with Denosumab presented with severe hypocalcaemia.

- Her presenting symptoms were peripheral paraesthesia, anorexia, leg weakness and bony pains.

\section{Lab results on admission

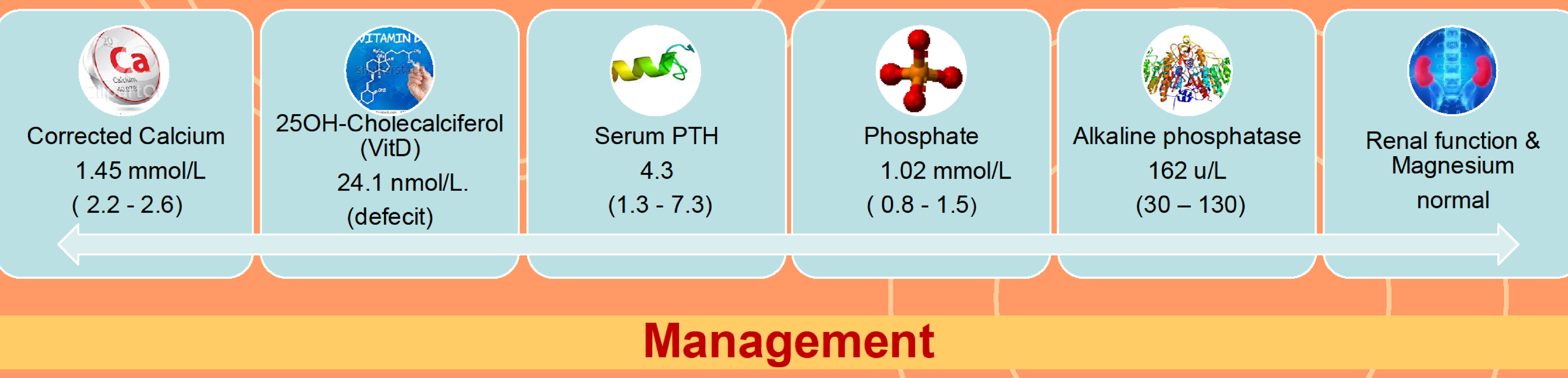

She was treated with intravenous calcium gluconate during symptomatic episodes. Vitamin $D$ deficiency was managed with high dose Coleclaciferol $(20,000 \mathrm{IU}, 3$ times a week for 12 weeks) and oral calcium equivalent to $6 \mathrm{~g}$ of elemental calcium was also commenced. Symptomatic hypocalcaemia persisted despite progressively increasing doses of elemental calcium equivalent to $9 \mathrm{~g}$ daily. In view of persistent hypocalcaemia, treatment with Bendroflumethiazide 2.5 $\mathrm{mg} / \mathrm{day}$ and Alfacalcidol $1 \mathrm{mcg} /$ day was instituted .The dose of Alfacalcidol was incrementally increased to $8 \mathrm{mcg} / \mathrm{day}$. Normocalcaemia was achieved in 16 weeks.

\section{Discussion}

Hypocalcaemia is an uncommon complication of malignancy and is caused by osteoblastic bone metastases. The putative mechanism is increased uptake of calcium by osteoblastic lesions. Hypocalcaemia in our patient was exacerbated by Denosumab therapy and Vitamin D deficiency. However, hypoparathyroidism in the context of severe hypocalcaemia was suggestive of impaired parathyroid reserve presumed secondary to microscopic malignant infiltration of the parathyroid glands.

\section{Conclusion}

Malignancy-related hypocalcaemia occurs almost exclusively with osteoblastic bone metastases and is generally associated with secondary hyperparathyroidism. Our case highlights the fact that microscopic malignant infiltration of the parathyroid glands can occur with advanced malignancy and result in severe refractory hypocalcaemia. Supra-physiological doses of elemental calcium and Vitamin D are generally required to induce and maintain normocalcaemia.

References:

1. Bouvier DP. Hypocalcaemia and an inappropriate endocrine response in osteoblastic metastatic breast cancer. South Med J 1989;12:1574-6.

2. Harley HAJ, Mason R, Phillips PJ. Profound hypocalcaemia associated with oestrogen treatment of carcinoma of the prostate. Med J Australia 1983;2:41-2.

3. Mariette X, Khalifa P, Boissonnas A, Sereni D, Cremer G. Hypocalcaemia due to parathyroid metastases. Eur J Med 1993;2:242-4.

4. Wiegand MC, Burshell A, Jaspan J, Odugbesan O. Case report: Clinical hypocalcaemia: the endocrine conference of the Alton Ochsner Medical Institutions and Tulane University Medical Center. Am J Med Sci 1994;308:255-8.

5. Riancho JA, Arjona R, Valle R, Sanz J, Gonzalez-Macias J. The clinical spectrum of hypocalcaemia associated with bone metastases. J Intern Med 1989;226:449-52. 